\title{
The Evolution of E-Commerce Payment
}

\author{
Chuan Lin \\ School of Business, Jinan University, Guangzhou, China \\ Email: 18813754415@163.com
}

How to cite this paper: Lin, C. (2017) The Evolution of E-Commerce Payment. Technology and Investment, 8, 56-66. https://doi.org/10.4236/ti.2017.81005

Received: December 13, 2016 Accepted: February 17, 2017 Published: February 20, 2017

Copyright $\odot 2017$ by author and Scientific Research Publishing Inc. This work is licensed under the Creative Commons Attribution International License (CC BY 4.0).

http://creativecommons.org/licenses/by/4.0/

\begin{abstract}
Firstly, a game model is established under unconstrained market conditions to illustrate the basic evolutionary rule of the market of e-commerce payment method. It is concluded that the establishment of e-commerce payment market is not normative under the unconstrained market conditions, which shows the importance of the introduction of the third party payment for the establishment of standardized e-commerce trading market. In this way, a standardized e-commerce market can be established. This paper analyses the model parameters to illustrate the strategies and methods to achieve good market behavior. And then it improves the model by adding legal supervision and penalties for illegal businesses and other market constraints. And it's proved that the regulation of market is very important in creating a good market environment and exit block. Finally, this paper gives some useful suggestions on how to form a good standard of market behavior.
\end{abstract}

\section{Keywords}

Evolutionary Game, Incomplete Information, E-Commerce Market, Trading Method

\section{Introduction}

In the traditional shopping mode, cash and carry are the most common way of trading. But, e-commerce model breaks the traditional rules, making a certain time and space difference between the cash and carry, which leads to a problem that should be the first to pay or the first to delivery. In e-commerce transactions, buyer and seller are in the case that they have never met and taken the trading activities in a virtual network environment. On the one hand, the seller worries about the arrears after the buyer receives the goods. On the other hand, the buyer worries about the payment without goods. In reality, there are always some unscrupulous sellers profiteering from fake products so that the buyers receive the products unqualified and not up to standard and thus suffer unnecessary losses. In addition, 
due to the incomplete information in the e-commerce market, the buyer can't determine the satisfactory sellers. They can only guess the general situation of the market after each shopping experience and modify their behavioral strategies to improve the shopping effectiveness. Under these circumstances, incomplete information may affect the seller's and the buyer's choice of behavioral strategies, causing market ultimately evolved and locked to bad situation. JY Wang, LM Cao (2008) [1] established a dynamic game model of imperfect information, and set the game income matrix. The paper used the Nash equilibrium to calculate the transaction results, and found that the third- party trading platform was conducive to the further improvement of the market. Liu B (2009) [2] established an evolutionary game model to the limited rational C2C E-commerce sellers' trade tactic selection. According to discussing the relationship of the model's parameters, he analyzed the long-term evolutionary trend of both good-credit and bad-credit $\mathrm{C} 2 \mathrm{C}$ E-commerce sellers' tactic selection under different conditions. Jun Wang (2009) [3] conducted a signal game to analyze the credit problems frequently happening in e-commerce. And some strategies have been put forward to promote the integrity between the buyer and seller. Yi Y (2003) [4] established an evolutionary game model that was constructed to study the basic evolution law of the credit market with no restriction. How to reach good market behavior is illustrated by analyzing and controlling model parameters. This paper introduces the regulation of the market to show how to make the normative e-commerce market come into being. G Jiang (2006) [5] establishes a model of evolutionary game theory in the condition of unconstrained market to illustrate the basic evolutionary law of consulting market according to the developing process of Chinese consulting market in hydropower project construction.

With the continuous development of e-commerce, e-commerce at this stage of the payment methods includes the following: payment gateway model; online banking model; third-party payment model; mobile payment model; cash on delivery.

After the research of Bo L (2006) [6] and so on, through the payment gateway and online banking to pay faster way, the customer's money can be transferred to the merchant's account in real time, greatly speeding up the turnover rate of funds; on the other hand, the payment process data encryption and other measures to a certain extent ensure the security of the payment.

Mobile payment is a new type of payment recently appeared, because it uses the convenience and popularity of mobile phones, and the market is very optimistic about the prospects. With the third party payment, the customers don't have to pay to the seller directly, and have the right to withdraw the payment if finding something wrong in the products, so as to avoid losses. This payment method is easy to be accepted and is currently the most commonly used payment. While the Cash on delivery has a certain application currently, it has higher requirement of trust online.

Because the-commerce in China has been in growth period, both the incomplete information and nonstandard behavior are unavoidable in e-commerce market. So the paper that tries to form standard rules of e-commerce market and 
make the market in inefficient state so as to withdraw from the lock could be very meaningful.

\section{Establishment and Analysis of Model}

Assume that in a "natural" (without regard to other constraints) market, the sellers and buyers trade strategically. It's supposed that considering the benefit, the buyers tend to pay for the goods after the delivery firstly, but during the negotiation with the sellers, they could insist cash on delivery (We call this choice B1), or not (B2). At the same time, assume that the seller will prefer to receive the payment first. But in the actual negotiations with the buyer the sellers will have two kinds of behaviors: insist on payment after delivery (S1) and do not insist on payment after delivery (S2).

Assume that without other constraints, the buyer and seller are like to break the rules of transaction, if there happens delivery without payment or payment without delivery. Because from the aspect of interests, it is profitable of receiving the payment without delivery or receiving the goods without paying. Assume that: 1) If B1 and S1 happen at the same time, deal can't work. 2) If B1 and S2 happen at the same time, because of the buyer's strong negotiation ability, there will come to an agreement of cash on delivery. 3) If B2 and S1 happen at the same time, there will form an agreement of cash before delivery due to seller's strong negotiation ability. 4) If B2 and S2 happen at the same time, the buyer and seller's negotiation ability is equal. So, the agreement of cash on delivery is as possible as the agreement of cash before delivery (Table 1).

In the table, $\mathrm{C}_{1}$ stands for the loss caused by the failure of the seller, $\mathrm{C}_{2}$ presents the loss caused by the failure of the buyer; $G_{D}>0$ means the utility surplus of the buyer which equals the total utility minus the commodity price paid; $G_{P}>0$ represents the seller's profit after selling the goods (total revenue minus the total cost); $\mathrm{E}>0$ means the extra profits that caused by sellers' receiving the payment without delivery or by buyers' receiving the goods without payment. Assume that the proportion of buyers taking strategy B1 in the buyer group is $\mathrm{p}$. And the proportion of sellers who adopt strategy S1 in the seller group is q. According to the Malthusian dynamic equation and the rule that the growth rate of the strategy is equal to its relative fitness, it means that as long as the Individual adopting the strategy has higher fitness than the average, the strategy grows. The kinetic equation is expressed as

$$
\begin{aligned}
& \bar{p} / p=e * A * Q-P * A * Q \\
& \bar{q} / p=e * B * Q-P * B * Q
\end{aligned}
$$

In the equation, $e=\{1,0\}$ is the unit vector, and $\mathrm{p}=\{\mathrm{p}, 1-\mathrm{p}\}$ is the hybrid strategy of $\mathrm{B} 1$ and $\mathrm{B} 2 . \mathrm{Q}=\{\mathrm{q}, 1-\mathrm{q}\}$ is the mixed strategy of $\mathrm{S} 1$ and $\mathrm{S} 2$. A and $\mathrm{B}$

Table 1. The payment matrix for the seller and buyer.

\begin{tabular}{ccc}
\hline buyer & & seller \\
& $\mathrm{S} 1$ & $\mathrm{~S} 2$ \\
$\mathrm{~B} 1$ & $-\mathrm{C}_{2},-\mathrm{C}_{1}$ & $\mathrm{G}_{\mathrm{D}}+\mathrm{E}, \mathrm{G}_{\mathrm{P}}-\mathrm{E}$ \\
$\mathrm{B} 2$ & $\mathrm{G}_{\mathrm{D}}-\mathrm{E}, \mathrm{G}_{\mathrm{P}}+\mathrm{E}$ & $\mathrm{G}_{\mathrm{D}}, \mathrm{G}_{\mathrm{P}}$ \\
\hline
\end{tabular}


represent the payment matrix for buyers and sellers, respectively. Then $e * A * Q$ and $P * A * Q$ denotes the fitness of the buyer adopting strategy $\mathrm{B} 1$ and the average fitness of the buyer group, respectively. And $e * B * Q$ and $P * B * Q$ represents the fitness of the seller adopting the strategy $S 1$ and the average fitness of the seller, respectively. So the dynamic equation of the e-commerce payment market can be drawn

$$
\begin{aligned}
& \bar{p}=p(1-p)\left[E-\left(C_{2}+G_{D}\right) q\right] \\
& \bar{q}=q(1-q)\left[E-\left(C_{1}+G_{P}\right) p\right]
\end{aligned}
$$

Proposition 1: If $C_{1}+G_{P}>E$ and $C_{2}+G_{D}>E$, system (2) shows that on the plane $M=\{(p, q) ; 0<=p, q<=1\}$, there are five equilibrium points of the evolutionary game between the buyer and the seller, which are unstable points $(0,0),(1$, $1)$ and stable points $(0,1),(1,0)$ and saddle points $F=\left(E / C_{1}+G_{P}, E / C_{2}+G_{D}\right)$.

Proof: Consider $\mathrm{C}_{1}+\mathrm{G}_{\mathrm{P}}>\mathrm{E}$ and $\mathrm{C}_{2}+\mathrm{G}_{\mathrm{D}}>\mathrm{E}$ only.

Because if $\mathrm{C}_{1}+\mathrm{G}_{\mathrm{P}} \leq \mathrm{E}$ and $\mathrm{C}_{2}+\mathrm{G}_{\mathrm{D}} \leq \mathrm{E}$, at least one of $\bar{p}$ or $\bar{q}$ is constantly greater than zero. If $\mathrm{p}$ increases from 0 to 1 , it means that the buyer will insist on cash on delivery otherwise withdraw from the market, making the market instable. And if $\mathrm{q}$ increases from 0 to 1 monotonously, the seller will insist on cash before delivery, otherwise the seller will withdraw from the market, making the market instable too. It's also possible that $\mathrm{p}$ and $\mathrm{q}$ increase from 0 to 1 at the same time. The buyer insists on cash on delivery and the seller insists on cash before delivery, in which the market can't be formed.

When $C_{1}+G_{P}>E$ and $C_{2}+G_{D}>E$, it is obvious that there are five equilibrium points in system $(2)$, which are $(0,0)(1,1)(0,1)(1,0)$ and $F$. With the analysis on them, we can see that $(0,0)$ and $(1,1)$ are instable source points, $(0$, $1),(1,0)$ are stable import points and $F$ is the saddle point. The phase diagram of the system (2) that is given by Proposition 1 is shown in Figure 1.

The analysis of Figure 1 shows that the system converges at $(0,1)$ when the initial state is in the upper left region (called region $G$ ) of the line in which the point $(0,0)$, point $(1,1)$ and point $\mathrm{F}$. It means that all the sellers insist on cash

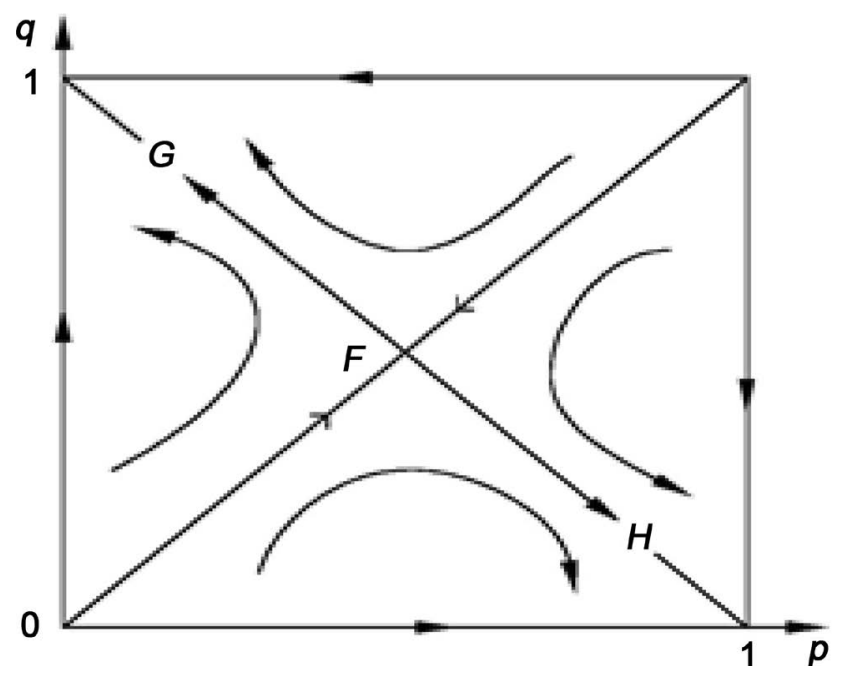

Figure 1. Evolution rule of e-commerce without constraints. 
before delivery, and the buyers do not insist on cash on delivery. When the initial state is in the bottom right region (called region $\mathrm{H}$ ) of the line in which the point $(0,0)$, point $(1,1)$ and point $F$, the system will converges at $(1,0)$. That is to say all the buyers insist on cash on delivery and the sellers do not insist on cash before delivery.

It's found that the long time evolution of e-ecommerce would be completely different and not normative only with buyer and seller in the market. Both the two state that the sellers don't deliver the goods after the buyers' payment and that the buyers don't pay for the goods after the sellers' delivery are evolved stable. In either state, the participant taking the other behavior strategy would be chosen to leave by the market.

The reason why the normative market behavior can't be established is that the buyers and sellers are invisible. So, with the need to introduce a mechanism for eliminating the disadvantages of invisible buyers and sellers, the third-party payment emerges as the time requires. It's also called the third-party depository. The buyer pays for the goods to the third-party's account firstly. Receiving the payment, the third-party then notifies the seller to deliver the goods and transfer the money the buyer paid to the seller after the buyer receiving the goods. It works and solves many troubles within the transaction.

With the participation of the third-party payment, payment matrix for the seller and buyer changes. When the buyer take the strategy of B1 and the seller take the strategy of S2, there will come to an agreement of cash on delivery with the buyer's strong negotiation ability. Then it can avoid the buyer's arrears very well and form the normative e-commerce payment market. But the seller is likely to deliver the shoddy or fake to obtain additional profits. In this case, the payment matrix of the buyer and seller is shown in Table 2.

$\mathrm{E}_{0}$ in the table indicates the seller's additional profits for selling shoddy and fake.

The dynamic equation of e-commerce market turns out:

$$
\begin{aligned}
& \bar{p}=p(1-p)\left[E_{0} / 2-\left(C_{2}+G_{D}-E_{0} / 2\right) q\right] \\
& \bar{q}=q(1-q)\left[E_{0} / 2-\left(C_{1}+G_{P}+E_{0} / 2\right) p\right]
\end{aligned}
$$

Proposition 2 : If $C_{2}+G_{D}>E$, then the system (3) shows that on the plane $M$ $=\{(\mathrm{p}, \mathrm{q}) ; 0 \leq \mathrm{p}, \mathrm{q} \leq 1\}$, there are five equilibrium points of evolutionary game between the buyer and seller, which are unstable points $(0,0),(1,1)$ and stable points $(0,1),(1,0)$ and saddle points $F=\left(E_{0} / 2 / C_{1}+G_{P}+E_{0} / 2, E_{0} / 2 / C_{2}+G_{D}-\right.$ $\left.\mathrm{E}_{0} / 2\right)$.

Table 2. The payment matrix for the seller and buyer.

\begin{tabular}{ccc}
\hline buyer & seller \\
\hline S1 & $\mathrm{S} 2$ \\
\hline B1 & $-\mathrm{C}_{2},-\mathrm{C}_{1}$ & $\mathrm{G}_{\mathrm{D}}, \mathrm{G}_{\mathrm{P}}$ \\
B2 & $\mathrm{G}_{\mathrm{D}}-\mathrm{E}_{0}, \mathrm{G}_{\mathrm{P}}+\mathrm{E}_{0}$ & $\mathrm{G}_{\mathrm{D}}-\mathrm{E}_{0} / 2, \mathrm{G}_{\mathrm{P}}+\mathrm{E}_{0} / 2$ \\
\hline
\end{tabular}


Proof: Consider the condition $\mathrm{C}_{2}+\mathrm{G}_{\mathrm{D}}>\mathrm{E}$ only.

If $\mathrm{C}_{2}+\mathrm{G}_{\mathrm{D}} \leq \mathrm{E}, \bar{p}$ is greater than or equal to zero constantly. Then on the plane $M=\{(p, q) ; 0 \leq p, q \leq 1\}$, p will increase from 0 to 1 monotonically, and the buyer will insist on cash on delivery. Otherwise the buyer will quit from the market, making the market instable. So the condition that $C_{2}+G_{D} \leq E$ is not considered here.

When $C_{2}+G_{D}>E$, It is clear that system (3) has five equilibrium points, which are $(0,0),(1,1),(0,1)(1,0)$ and $\mathrm{F}$. And after the local stability analysis with the five points, It is found that $(0,1)$ and $(1,0)$ are the instable source points, $(0,1),(1,0)$ are stable import points and $\mathrm{F}$ is the saddle point. The phase diagram of the system (3) that is given by Proposition 2 is shown in Figure 2.

The analysis of Figure 2 shows that the system converges at $(0,1)$ when the initial state is in the upper left region (called region $G$ ) of the line in which the point $(0,0)$, point $(1,1)$ and point $\mathrm{F}$. It means that all the sellers insist on cash before delivery, and the buyers do not insist on cash on delivery. When the initial state is in the bottom right region (called region $\mathrm{H}$ ) of the line in which the point $(0,0)$, point $(1,1)$ and point $F$, the system will converges at $(1,0)$. That is to say all the buyers insist on cash on delivery and the sellers do not insist on cash before delivery.

It follows that in the long time, with participation of the third-party payment, the evolution of e-commerce payment market will be very different from the one without the third-party payment. One evolutionary result is the more normative and reasonable market where the seller deliver the quality goods and the buyer pay for the goods after receiving. Another evolutionary result is not standard. And at last the buyer will take the risk of paying for the fake or shoddy. Both the results are evolutionarily stable and in either of them, the participants who take another behavioral strategy will disappear due to the choice of market.

\section{Parameter Analysis and Regulation}

Assume that the initial conditions of the system are stochastic and random distribution. On the plane $M=\{(p, q) ; 0 \leq p, q \leq 1\}$, the purpose of analyzing the

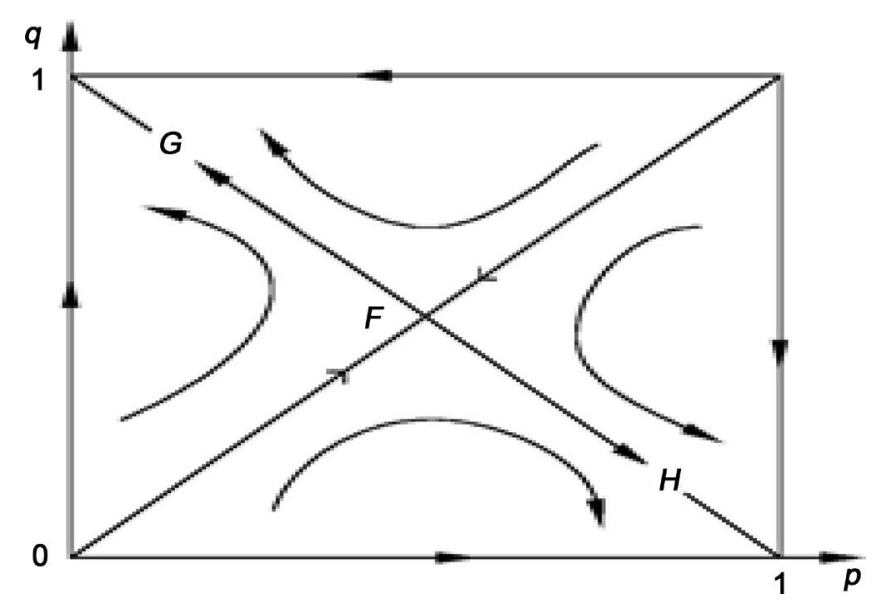

Figure 2. Evolution rule of e-commerce with the third-party payment and no constraints. 
parameters is to know whether the change of parameters can make the region $\mathrm{G}$ narrowed and the region $\mathrm{H}$ broadened in Figure 2, which make the point $\mathrm{F}$ move to upper left so that the system comes to be stable $(1,0)$, or not. The following analysis of the parameters of the model tries to find its impact on market evolution and to impose possible regulation, aiming to direct the market to evolve in a correct direction.

\subsection{The Utility Surplus $G_{D}$ the Buyer Obtain for Buying the Goods}

The market determines the price of commodity, and different prices have different effects on market behavior on the other way round. When $G_{D}$ increases (the price decreases), the coordinate $\mathrm{pF}$ of point $\mathrm{F}$ does not change but $\mathrm{q}^{\mathrm{F}}$ decreases. That is, point $\mathrm{F}$ will move toward the below of $\mathrm{M}$. the region of $\mathrm{H}$ will broaden but the region of $\mathrm{G}$ will narrow. This shows that the price of commodity decreases in the appropriate range, and the seller can get higher normal income making the possibility that the seller deliver the fake decrease but the possibility that the market tends to be normative increase. If the price falls, in the case that the seller's normal income decrease, the motivation the seller have will be enhanced.

\subsection{Additional Income $\mathrm{E}_{0}$}

When $\mathrm{E}$ increases, both $\mathrm{p}^{\mathrm{F}}$ and $\mathrm{q}^{\mathrm{F}}$ will increase, but $\mathrm{q}^{\mathrm{F}}$ increases at a larger range. It means that point $F$ will move to the upper right corner of $M$, enlarging the region of $\mathrm{H}$ but narrowing the region of $\mathrm{G}$. On the contrary, when E decreases, the region of $\mathrm{H}$ will be narrowed but the region of $\mathrm{G}$ will be enlarged. On the surface, selling fake goods can get more additional benefits, so the seller should prefer cash before delivery. But in fact the possibility that the buyer insist on cash on delivery increases. It indicates that the self-organization of the market plays an important role, limiting the seller's motivation to deliver the fake.

\subsection{The Loss $C_{1}$ the Seller Suffer for Not Reaching an Agreement}

When $\mathrm{C}_{1}$ increases, $\mathrm{p}^{\mathrm{F}}$ will become smaller but $\mathrm{q}^{\mathrm{F}}$ stay unchanged. The point $\mathrm{F}$ will move to the left of $\mathrm{M}$, and the region of $\mathrm{H}$ will be enlarged but the region of $\mathrm{G}$ will be narrowed. Conversely, when $\mathrm{C}_{1}$ decreases, the region of $\mathrm{H}$ will be narrowed but the region of $\mathrm{G}$ will be enlarged. It's obvious that the increase of the loss $C_{1}$ the seller suffers for not reaching an agreement is very effective to decrease his motivation for delivering the fake in the agreement of cash before delivery. In fact, the loss the seller suffers for not reaching an agreement is related to the size of the e-commerce market and the replacement of commodity. If the quantity of the buyer is too small, the seller is not easy to find the other buyers because of the buyer's monopoly so that the loss seller suffers for not making the deal would be increased. However if the quantity of the buyer is large enough, the loss for not reaching an agreement would be decreased.

\subsection{The Loss $C_{2}$ the Buyer Suffer for Refusing the Purchase}

When $\mathrm{C}_{2}$ increases, $\mathrm{p}^{\mathrm{F}}$ will stay unchanged and $\mathrm{q}^{\mathrm{F}}$ will become smaller. It means 
that point $\mathrm{F}$ will move to the bottom of $\mathrm{M}$ and the region of $\mathrm{H}$ will get smaller while the region of $\mathrm{G}$ will become larger. On the other hand, when $\mathrm{C}_{2}$ decreases, the region of $\mathrm{H}$ will become larger but the region of $\mathrm{G}$ will get smaller. This shows that when the loss that the buyer suffers for refusing the purchase increases, the buyer's negotiation ability will be weakened and increase the possibility that the seller insist on cash before delivery. The loss that the buyer suffers for refusing the purchase is related to the scale of credit market and the alternative purchasing mode. If the scale of e-ecommerce is relatively small, it's difficult for the buyer to find other sellers so that the possibility that the buyer insist on cash on delivery would be reduced. When the sellers are faced with strong competition, the motivation that the seller insists on cash before delivery would be weakened too.

In short, the e-commerce market has its own operation law, and the model can reflect some of the major market laws. According to these laws the market can be regulated in a good direction.

\section{Model Improvement}

The model above does not take into account the control and supervision of the law, as well as buyer's rising awareness of the rights. So the seller can't get additional income from the fake and shoddy. If the model above considers the supervision from the law, the buyer will resort to law when receiving the fake or shoddy so that some unruly sellers will be punished. In this case, suppose the loss the seller suffer is $\mathrm{R}$ and the cost the buyer pay for recovering the loan is $\mathrm{K}$ which is larger than 0 . Then the payment matrix of the buyer and the seller is shown in Table 3.

The dynamic equation of e-commerce payment market becomes

$$
\begin{aligned}
& \bar{p}=p(1-p)\left[K / 2-\left(\mathrm{C}_{2}+\mathrm{G}_{\mathrm{D}}-K / 2\right) q\right] \\
& \bar{q}=q(1-q)\left[R / 2-\left(C_{1}+G_{P}+R / 2\right) p\right]
\end{aligned}
$$

Proposition 3: If $C_{2}+G_{D}>K$, the system (4) shows that there are four equilibrium points of the evolutionary game between the buyer and the seller on the plate $M=\{(p, q) ; 0 \leq p, q \leq 1\}$. They are saddle points $(0,0),(0,1)$ and the import point $(1,0)$ and the source point $(1,1)$.

Proof: This paper only considers the condition that $\mathrm{C}_{2}+\mathrm{G}_{\mathrm{D}}>\mathrm{K}$, and the reason is the same as proposition 1 or 2 explained above. So If $C_{2}+G_{D}>K$, the system (4) shows that there are four equilibrium points of the evolutionary game between the buyer and the seller. They are saddle points $(0,0),(0,1),(1,0),(1$, $1)$. And after the local stability analysis with the points, It is found that $(0,0)$ and

Table 3. The payment matrix of the buyer and the seller.

\begin{tabular}{ccc}
\hline buyer & \multicolumn{2}{c}{ seller } \\
\hline \multicolumn{1}{c}{$\mathrm{S} 1$} & $\mathrm{~S} 2$ \\
\hline $\mathrm{B} 1$ & $-\mathrm{C}_{2},-\mathrm{C}_{1}$ & $\mathrm{G}_{\mathrm{D}}, \mathrm{G}_{\mathrm{P}}$ \\
$\mathrm{B} 2$ & $\mathrm{G}_{\mathrm{D}}-\mathrm{K}, \mathrm{G}_{\mathrm{P}}-\mathrm{R}$ & $\mathrm{G}_{\mathrm{D}}-\mathrm{K} / 2, \mathrm{G}_{\mathrm{P}}-\mathrm{R} / 2$ \\
\hline
\end{tabular}


$(0,0)$ are the saddle points, the $(1,1)$ is the source point and the $(1,0)$ is the stable import point. The phase diagram of the system (4) that is given by Proposition 3 is shown in Figure 3.

In Figure 3, starting from any initial state in plate $M$, the system will converge to $(1,0)$. That means all the buyers insist on cash on delivery or the buyer don't insist on cash on delivery but firmly use the weapon of law to protect their own interests when receiving the fake. From the aspect of seller, when faced with penalty of fake, the seller tends to take legal strategies. And e-commerce payment market will eventually evolve into a standardized market. However, the buyer's awareness of protecting rights and law enforcement agency's enforcement efforts have a great relationship with the formation of the standardized market. The buyer's excessive tolerance and the law enforcement agency's lax enforcement may cause the proliferation of e-commerce market irregularities.

\section{Conclusions}

Conclusion 1: only with buyer and seller in the market, the normative e-commerce market is not established.

From Figure 1, we can see that when there are only sellers and buyers in the market without constraints, the normative e-commerce payment market can't be formed. It needs to have the participant of the third-party payment to overcome the flaws of distrust in transaction.

Conclusion 2: The evolution path of e-commerce market is sensitive to the initial state of the market. E-commerce market evolution has path dependence.

As shown in Figure 2, after the e-commerce market is established, the e-commerce market will evolve into a non-standard market when the initial state is within the $\mathrm{G}$ region. When the initial state is in the $\mathrm{H}$ region, the e-commerce market will evolve into a relatively reasonable and normative market. Obviously, the evolution path of e-commerce market is influenced by the initial state of the market. That means the evolution of e-commerce market is path-dependent.

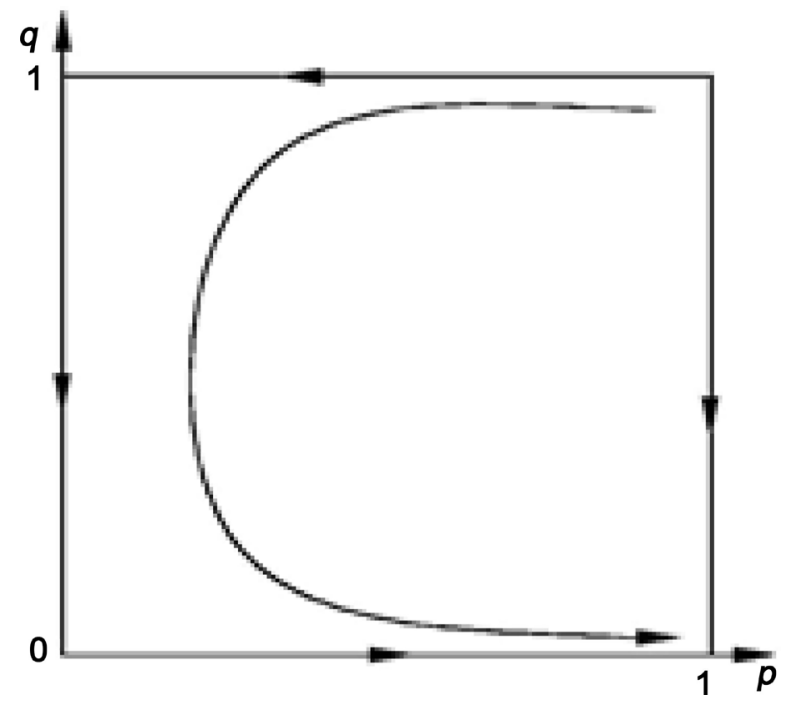

Figure 3. Evolution rule of e-commerce with the supervision from the law. 
Therefore, if an accidental factor makes the conditions of market in the G region, the market will move towards non-performance direction and become worse and worse, and ultimately is "locked" in a bad state. So the buyer wants to enhance the sense of shopping safety, and tends to check the business license and legality of the seller when shopping online. And the seller is firm to use the legal means to protect their interests when receiving the fake or shoddy. In this way, the market will enter a virtuous circle, and eventually evolves into the reasonable market.

If the system enters into a suboptimal or inefficient state, the path that exits from the suboptimal or inefficient state depends on the various factors that form the self-reinforcing mechanism. In the e-commerce market, the mechanism of increasing revenue can be derived from the various effects of the market itself, such as synergy. As long as the law enforcement agencies, the seller and the buyer have a strong information communication and take the same strategies, the alternative path may be realized.

Conclusion 3: In the e-commerce market, to join the government's legal supervision can make the market eventually evolved into a reasonable market, which is the government to provide a theoretical basis for the implementation of e-commerce market regulation.

Figure 3 shows that the e-commerce payment market under the supervision of the law can develop along the virtuous circle and ultimately evolve into a more rational and standardized market. Even if the e-commerce payment market has begun with the path of inefficient evolution, the market can exit from the inefficient path of "blocking" and make the alternative path realized, as long as the law enforcement agencies take the powerful supervision.

China is in the developing period of the Internet economy. There still exists much non-standard behavior in the e-commerce market. In order to make the market normative, the first is to raise the awareness of network security and the human rights, and improve market management mechanism to prevent the locked market, making sure that the market can develop along with the merit path. Repeating like this, the increasing income makes the e-commerce payment market develop along the virtuous circle and eventually evolve into a normative market.

\section{References}

[1] Cao, L.M. (2008) An Analysis of Online Shopping Trust Based on Imperfect Information Game. Computer \& Digital Engineering, 36, 70.

[2] Liu, B. and Su, S. (2008) An Evolutionary Game Analysis of C2C E-commerce Sellers' Trade Tactic Selection. 4th International Conference on Wireless Communications, Networking and Mobile Computing, 12, 1-6.

[3] Wang, J. (2009) Game Theory Analysis on Information Asymmetries in C2C E-Commerce. Journal of Wuhan University of Technology, 31, No. 10.

[4] Yi, Y. (2003) Evolution and Control of Credit Market of China. Journal of Southeast University, 3, 45-48.

[5] Jiang, G., et al. (2006) Consulting Market Evolution and Adjustment of Hydropow- 
er Project in China. The Journal of American Science, 2, 66-73.

[6] Liu, B. (2006) Present Situation and Prospect of E-Commerce Payment in China. Journal of Chongqing Radio Television University, 18, 30-32.

Submit or recommend next manuscript to SCIRP and we will provide best service for you:

Accepting pre-submission inquiries through Email, Facebook, LinkedIn, Twitter, etc. A wide selection of journals (inclusive of 9 subjects, more than 200 journals)

Providing 24-hour high-quality service

User-friendly online submission system

Fair and swift peer-review system

Efficient typesetting and proofreading procedure

Display of the result of downloads and visits, as well as the number of cited articles Maximum dissemination of your research work

Submit your manuscript at: http://papersubmission.scirp.org/

Or contact ti@scirp.org 